\title{
Nachruf auf Medizinalrat Dr. Gerhart Feucht
}

Traurig geben wir das Ableben unseres langjährigsten Mitgliedes, Herrn Dr. Gerhart Feucht, bekannt, der im 98. Lebensjahr von uns gegangen ist. Gerhart trat bereits im Gründungsjahr 1954 unserer Gesellschaft bei. Er gestaltete, formte und prägte als erster Generalsekretär die Entwicklung der Österreichischen Gesellschaft für Akupunktur (ÖGA). Gemeinsam mit Prof. Dr. Johannes Bischko und Dr. Hans Bartunek war er ein wesentlicher Wegbereiter und Vordenker für die Akupunktur in Österreich.

Geboren am 17.02.1922, musste er bereits 1940, mit 18 Jahren, den Militärdienst im 2. Weltkrieg antreten. Nach mehreren Verwundungen wurde er dann 1945 in Ostpreußen von den Russen gefangen genommen, nach Russland transportiert und zum Arbeitsdienst gezwungen. Schon in der Gefangenschaft arbeitete er als „Arzt“ und lernte „by doing", wie man trotz fehlender Medikamente heilen kann. Im Jahr 1947 konnte er nach Österreich zurückkehren und studierte sofort Medizin. Nach seiner Promotion 1952 arbeitete er zunächst unbezahlt, dann als Dauersekundararzt im Wiener Rochusspital, wo er Dr. Johannes Bischko kennenlernte, der dort Oberarzt an der chirurgischen Abteilung war. Gemeinsam beschäftigten sie sich mit dem ganz neu nach Europa gekommenen Wissen über Akupunktur, Gerhart interessierte sich jedoch auch sehr für Homöopathie und andere Grenzgebiete der Medizin. Nach Gründung der Österreichischen Gesellschaft für Akupunktur 1954 wurde auch auf internationaler Ebene zusammengearbeitet. Gerhart organisierte bereits 1957 den Weltkongress für Akupunktur in Wien (siehe auch Editorial der Deutschen Zeitschrift für Akupunktur 1/2017), war gefragter Referent bei Kongressen, publizierte viel und engagierte sich auch in der 1958 gegründeten Akupunkturambulanz an der Allgemeinen

Deutsche Zeitschrift für Akupunktur 2019. 62 (4): 286

https://doi.org/10.1007/s42212-019-00226-7

(c) Springer Medizin Verlag GmbH, ein Teil von

Springer Nature 2019
Wiener Poliklinik in der Mariannengasse im 9. Wiener Gemeindebezirk. Jeden Mittwoch war Gerhart nun ein Wegbereiter für viele Ärzte, die dort akupunktieren lernten, lehrte und zeigte vor, wie sehr die Akupunktur den vielen Patienten, die in diese Ambulanz strömten, helfen kann. Sein spezielles Interesse galt auch hauchdünnen Silber- und Goldfolien, die er auf Akupunkturpunkte und Störfeldzonen platzierte, um ein energetisches Gleichgewicht zu erzielen.

Gerhart, der uns immer mit seiner liebenswürdigen und bescheidenen Art beeindruckte, pflegte engste Kontakte zum Histologen und Entdecker des Grundsystems, Univ. Prof. Dr. Alfred Pischinger (1899-1983), und zum Wiener Gesundheitsstadtrat, Prof. Dr. Alois Stacher. Gemeinsam mit Prof. Bischko gründete diese Gruppe dann auch Boltzmann Institute sowohl für Akupunktur als auch für Grenzgebiete der Medizin, um die Forschung in diesen Bereichen anzukurbeln.

Trotzdem blieb Gerhart am liebsten „Praktiker". In seiner Ordination gab sich die ganze Wiener "Gesellschaft" die Türklinke in die Hand. Durch seine Therapieerfolge bei vielen Persönlichkeiten und Multiplikatoren gelang es ihm, den Ruf der Akupunktur als renommierte und populäre Heilmethode in Wien und Österreich schon in den 1970er-Jahren zu etablieren. Als hervorragender Diagnostiker und Arzt war sein Ruf so groß und seine Meinung so gefragt, dass er bis kurz vor seinem Tod immer wieder als Konsiliarius beigezogen wurde.

Seine spirituelle Heimat war der Malteser Ritterorden, in den er 1979 aufgenommen wurde und darauffolgend zum Magistral-Großkreuz-Ritter rangerhöht wurde. Er engagierte sich im Rahmen des Malteser Hospitaldienstes bei unzähligen Lourdes-Zügen und war auch Chefarzt beim Papstbesuch 1982 in Wien sowie 20 Jahre lang Ordensarchivar.

Privat führte er eine gute Ehe und pflegte liebevoll sowohl seine Mutter als auch im hohen Alter seine Frau.

Großzügigerweise hat Gerhart der ÖGA einen Teil seiner umfangreichen Fachbibliothek und einige Originalbriefe und Dokumente vermacht, die wir dank-

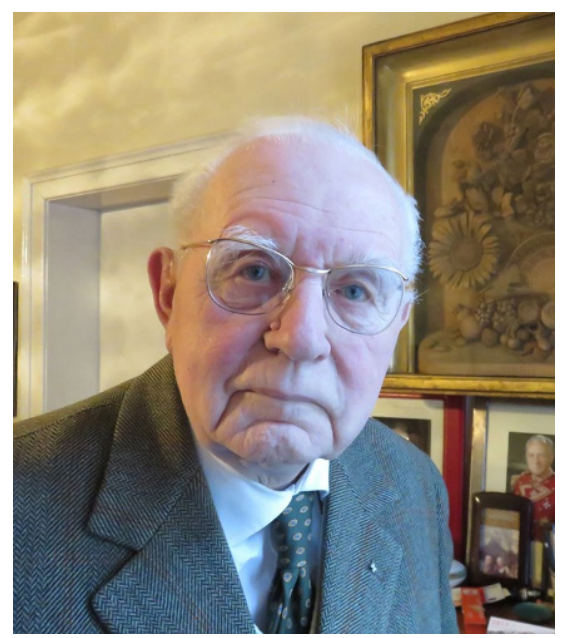

Medizinalrat Dr. Gerhart Feucht

bar in Ehren halten werden und die für uns stets eine Erinnerung an ihn sein werden.

Lieber Gerhart, wir bedanken uns für Deine 65-jährige Mitarbeit und die Unterstützung der Österreichischen Gesellschaft für Akupunktur. Mutig hast Du mithilfe ,innovativer" Methoden, die damals noch kaum etabliert waren, immer den kranken Menschen in den Mittelpunkt gestellt und all Deine Kraft eingesetzt, um Leid zu vermindern. Als ausgezeichneter Lehrer hast Du unzählige Ärzte und Ärztinnen in Österreich in Akupunktur ausgebildet und sie an Deinem Wissen teilhaben lassen. Dadurch hast Du einen großen Beitrag zur Etablierung der Akupunktur in Österreich, aber auch zur ganzheitlichen Betrachtungsweise unserer Patienten geleistet.

\section{Korrespondenzadresse}

\section{Karin Stockert}

Österreichische Gesellschaft für Akupunktur (ÖGA)

Riedelgasse 5, 1130 Wien, Österreich 